
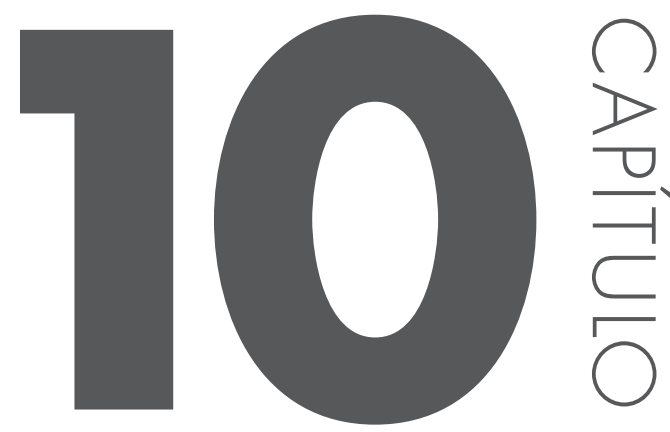

\title{
A FORMAÇÃO CONTINUADA DE PROFESSORES DA EDUCAC̣ÃÓ INFANTIL DA REDE MUNICIPAL DE CATALÃO/GO
}

\author{
Duarte, Luciana Cândida ${ }^{1 *}$; Silva, Altina Abadia ${ }^{2}$ \\ ' Secretaria Municipal de Educação de Catalão - PPGEDUC/Regional Catalão - UFG \\ 2 Faculdade de Educação - PPGEDUC/Regional Catalão - UFG \\ *email: proflu1@hotmail.com
}

\section{RESUMO}

Na Lei de Diretrizes e Bases (LDB), promulgada em 1996, já entendia que a faixa etária até os seis anos de idade é a primeira etapa da educação da criança. Por isso deveria ser oferecida em creches ou entidades equivalentes até os três anos e em pré-escolas dos quatro aos seis anos de idade. Atualmente, para adequação do ensino de nove anos, a LDB foi alterada através da Lei $\mathrm{n}^{\circ} 11.114 / 05$ e, com isso se diminuiu a oferta da educação infantil. Ocorre que, até hoje, muitos entende a educação infantil do zero aos três anos como uma etapa em que as crianças necessitam apenas de cuidados e afeto. Em consequência disso, a formação dos profissionais em educação não tinham o merecido tratamento. Esta pesquisa 
propõe analisar as práticas de formação continuada que a Secretaria Municipal de Educação de Catalão/GO disponibilizou para qualificação dos professores da Educação Infantil, no período de 2000 a 2010. Nossos objetivos de análises remetem a reflexões sobre responsabilidade social, políticas educacionais e os índices de avaliação do governo. A nossa pesquisa com recorte etnográfico teve como foco professores de cinco instituições de ensino, nas análises preliminares investigamos sobre a atuação docente e as condições de trabalho a que são submetidos os (as) professores (as) da Educação Infantil do município de Catalão/GO. Dados que fortalece nossa percepção quanto à necessidade de formação continuada como processo contínuo de negociações e descobertas que proporcionam novas fundamentação e experiências na ação pedagógica educacional.

Palavras-chave: Formaç̃õo Continuada; Educação Infantil; Políticas Públicasr.

Revisado pela Orientadora Altina Abadia Silva, contato: email: tina@wgo.com.br

Duarte, Luciana Cândida; Silva, Altina Abadia; "A FORMAÇÃO CONTINUADA DE PROFESSORES DA EDUCAÇÃO INFANTIL DA REDE MUNICIPAL DE CATALÃO/GO", p. 169-186 . In: Seminário de Pesquisa, Pós-Graduação e Inovação da Regional Catalão (2. : 2014 : Goiás) Coletânea Interdisciplinar em Pesquisa, Pós-Graduação e Inovação - Volume 2 : Humanidades e Letras. Anais [livro eletrônico] / organizado por Adriana Freitas Neves, Idelvone Mendes Ferreira, Maria Helena de Paula, Petrus Henrique Ribeiro dos Anjos. São Paulo: Blucher, 2015. ISBN: 978-85-8039-111-4, DOI 10.5151/9788580391114-V2_Cap10 


\section{INTRODUC̣ÃO}

Pensar os desafios enfrentados pelos professores da Educação Infantil quanto à formação profissional, na Rede Municipal de Educação de Catalão/GO, requer, antes de tudo, uma contextualização social, econômica e cultural, visto que acreditamos que essas conjunturas interferem diretamente nas práticas desses sujeitos e na busca ou não pela formação continuada. De acordo com dados do Censo 2011, do Instituto Brasileiro de Geografia e Estatística - IBGE, o município de Catalão/GO, conta com uma população de 84.964 habitantes. Localizado a $261 \mathrm{~km}$ da Capital, é geograficamente favorecido por constituir rota de ligação entre os grandes centros urbanos, e econômicos do Brasil, como Distrito federal, Goiânia, São Paulo e Uberlândia possibilitando o ir e vir das pessoas, a troca de experiências, informações e, logo, o aprimoramento profissional dos moradores da região. Há na cidade de Catalão, vinte e seis estabelecimentos Ensino, sendo dezoito de Educação Infantil (creches e préescolas) pertencentes à rede municipal de educação, as quais são destinadas a atender uma população de 1.905 um mil novecentos e cinco alunos. A rede municipal também dispõe com uma equipe formada por cento e dezoito professores, sendo que, desse total, noventa e sete possui formação superior, e vinte e um apenas o Ensino Médio e ou curso profissionalizante, o que revela um elevado índice de formação e capacitação.

Em relação à Educação infantil é possível notar muitos avanços, quanto à infraestrutura e remuneração profissional, mas é verdadeiro afirmar também que quem trabalha principalmente nos Centros Municipais de Educação Infantil (CMEIs) ainda sofre de grande preconceito e enfrenta dificuldades para o desenvolvimento do seu trabalho. Exatamente porque, num passado recente, muitos educadores, inclusive ligado ao antigo sistema de creches, defenderam que do zero aos três anos a criança necessita de cuidados físicos e precisava manter vínculo com uma só professora como resultado, professores de crianças pequenas não tinham férias nem horário pedagógico para planejamento e estudo.

A situação dos profissionais que atuam na pré-escola (crianças de Quatro e cinco 5 anos) é melhor no que tange a formação, condições de trabalho e horários pedagógicos, mas vivem a realidade do "terceiro estágio", etapa fundamental para criança, saindo da educação infantil e passando para o ensino fundamental. Essa realidade requer que façamos uma análise mais detalhada.

Acreditando que a formação continuada possibilita um conjunto de “ações” capazes de formar seres humanos autônomos e livres no exercício de suas práticas, propomos analisar quais as práticas de formação continuada 
foram oferecidas aos professores de Educação Infantil da rede municipal de Catalão/GO, na última década. Para tanto, trazemos à tona reflexões sobre responsabilidade social e individual, políticas educacionais, direito à formação e o papel da escola. Entendendo por formação continuada a possibilidade que o professor dispõe para pensar e repensar suas práticas pedagógicas, revitalizando ou fazendo reviver, constantemente, seu papel de sujeito transformador da realidade. Assim acredita-se que a formação continuada:

[...] não é um processo organizado para suprir deficiências de uma formação insuficiente, ruim ou aligeirada. Não participamos deste processo para que possamos aprender coisas que deixaram de ser destacadas no nosso processo de formação básica, uma vez que nenhum curso poderia dar conta de discutir todas as nuances e dilemas ocorridos no cotidiano. Assim, afirmamos que a formação continuada é a possibilidade constante de discutir, com interlocutores privilegiados, dimensões escolhidas do trabalho docente (SADALLA, 2008, p. 08).

Embora não tenha sido pensada para suprir as deficiências de uma formação insuficiente, de pouca qualidade ou aligeirada, admitimos que muitas vezes a procura pelos títulos e a busca por melhores salários fazem com que os professores apenas colecionem títulos de pós-graduação latu sensu, e acabem por seguir a ótica do mercado produtivo, deixando de lado o essencial: a reflexão, a interlocução com os pares, a possibilidade de recriar, de interrogar, de pensar, de estabelecer o que quer, quando e como quer ensinar. Entendemos que essas práticas podem ser desenvolvidas por meio dos cursos de formação, os quais, quando feitos com compromisso e responsabilidade social, podem levar os educadores a descobrirem novas possibilidades de atuação.

Observando a política econômica, verificamos que no decorrer das décadas de 1980 e 1990 foram destinados incentivos governamentais no propósito de "formar" ou "re-formar" continuamente os profissionais da educação. Desde as Reformas Universitárias e também com a Reforma da Educação Superior, houve grande expansão de cursos destinados aos profissionais da educação, como podemos ler:

No tocante à pós-graduação e à pesquisa no país, observa-se um crescimento considerável, sobretudo nas ultimas décadas, em decorrência do maior investimento do poder publico na área e em razão do próprio crescimento da demanda por mestres e doutores. 
A implantação das diretrizes e das ações previstas, especialmente, no Plano Nacional de Pós-graduação (PNPG) 2005, 2010 estimulou e consolidou ainda mais a pós-graduação e a pesquisa nas universidades (OLIVEIRA, 2011, p. 120).

O Brasil conquistou destaque no cenário internacional pela implantação de cursos de pós-graduação, e com o crescimento dos cursos à distância, oferecidos pela UAB (Universidade Aberta do Brasil) nos últimos cinco anos. Em Catalão há um Campus da Universidade Federal de Goiás, um Centro de Ensino Superior, pertencente à rede particular, dois Pólos de Educação a Distância da UAB. Com essa significativa possibilidade de acesso ao ensino superior, cerca de $90 \%$ dos professores da Rede Municipal de Catalão/GO possuem formação neste nível. Entretanto, os resultados referentes à educação, nessa rede continuam negativos. Conforme podemos verificar no documento abaixo, no Índice de Desenvolvimento da Educação Básica (IDEB), algumas escolas de Catalão/GO tiveram as notas mais baixas do estado de Goiás, inclusive notas abaixo da meta em $18 \%$, conforme podemos ler no documento emitido pelo MEC:

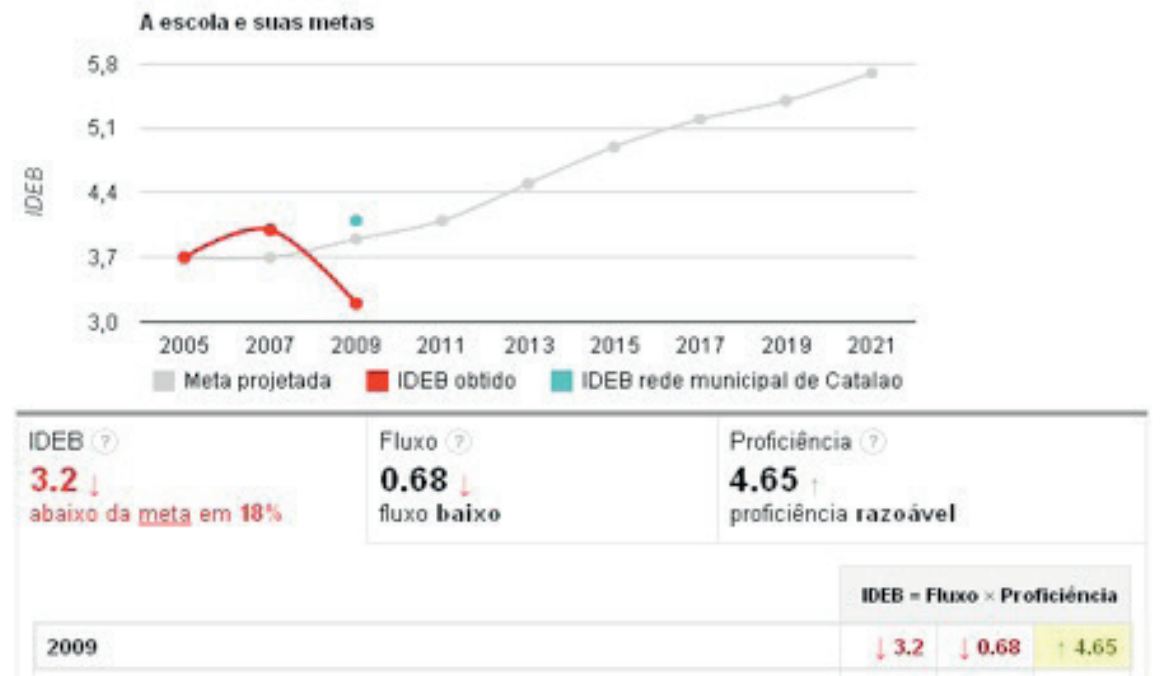

Fonte: Documento MEC 2010.

Sabe-se que esse índice é resultado da avaliação da "Provinha Brasil", que é realizada em duas etapas: no início do segundo ano, para avaliar o ensinoaprendizado adquirido no primeiro ano; e no final do mesmo ano, para avaliar o ensino adquirido durante o segundo ano escolar, bem como as boas ou más condições de trabalho do professor no sentido de reorientar a prática pedagógica. 
Se a educação é um processo contínuo, os conceitos básicos da matemática e da linguagem são formados nos anos iniciais da vida da criança, estabelecendo direta relação com a aprendizagem adquirida durante a Educação Infantil. Assim, acreditamos que essas notas negativas apresentadas pelos dados do IDEB (2010) têm reflexos oriundos de problemas no início da vida escolar. Partindo desse pressuposto, pensamos que o ensino oferecido nas instituições de Educação Infantil precisa ser melhor compreendido, e os professores devem ser mais assistidos e valorizados.

Não pretendemos aqui incentivar a idéia de que seja necessária uma prova para avaliar o ensino ou os professores da Educação Infantil, tampouco dizer que esse instrumento (Provinha Brasil), criado pelo MEC (Ministério da Educação), seja capaz de mensurar a qualidade da educação brasileira. Pelo contrário, acreditamos ser essa mais uma medida política, que possibilita a mensuração de dados quantitativos de um governo que prioriza, sobretudo, a quantidade, e não as medidas eficientemente capazes de interferir e melhorar a qualidade da educação, afinal, as políticas de educação de baixo custo têm sido priorizadas em vários governos. Também não podemos fechar os olhos e dizer que está tudo bem, afinal, os dados indicam que estamos longe da meta que, de acordo com o MEC, deveria ser nota 4.9, ainda em 2009.

O que propomos é levantar discussões e reflexões sobre esses dados que apontam antagonismos na educação, tendo em vista que, mesmo aumentado a oferta e demanda pelos cursos de pós-graduação, os resultados continuam negativos na rede municipal de educação de Catalão/GO.

Bem sabemos que é a formação continuada perpassa pela responsabilidade individual e social do professores, mas também, é um direito garantido na legislação brasileira, e cabe ao município proporcionar as condições necessárias para essa qualificação.

A reforma da Educação Superior e os incentivos políticos aplicados nas décadas de 1980 e 1990 abriram cenário para novos rumos na pesquisa. Nesse contexto, houve também uma grande expansão das temáticas, problemáticas, abordagens metodológicas e produções dos trabalhos científicos. Segundo Gatti (2001, p. 67) "Os temas ampliam e se diversificam". Assim, passamos a investigar não apenas o contexto e o impacto do produto, os quais podem ser controlados pela experimentação, mas também os processos, os conflitos e a experiência dos próprios pesquisadores, examinando as situações "reais" do cotidiano e da vida escolar.

Diante desse cenário, buscamos não apenas o rigor, mas também a qualidade da pesquisa em Educação, respondendo questionamentos sobre a 
natureza, os métodos e as técnicas utilizadas para a realização dos estudos no campo educacional, a fim elaborar um "discurso" que seja próprio da área do saber, pois, até então, eram os sociólogos, os psicólogos, os matemáticos e outros que pensavam e produziam sobre a educação. Para Charlot (2006), esse momento caracteriza um marco para definir qual seja nossa postura e o nosso discurso frente às pesquisas, conforme podemos ler:

Em outras palavras, o discurso hoje dominante no campo da aprendizagem não vem da pesquisa em educação, mas de outros campos de pesquisa. (...) o discurso “dos outros” é importante, é preciso levá-lo em conta. Mas é preciso também saber o que faz a pesquisa educacional (CHARLOT, 2006 p. 13).

Ao discutir a pesquisa educacional, indagamos sobre as teorias, o método, a coleta dos dados, as análises e os "fins" ou resultados dessas produções. Após muitos pontos e contrapontos, admitimos a subjetividade e a capacidade de produzirmos conhecimento científico $\mathrm{n}$ as $\mathrm{p}$ esquisas e ducacionais, $\mathrm{s}$ e observado com rigor o método e os procedimentos adequados a cada investigação. O que Gatti (2001, p. 73) coloca é que o "pensamento humano mantém uma relação dialética na construção das teorias vinculadas à pratica social de seus construtores e dos quais as utilizam". Tanto o sujeito quanto o objeto em estudo podem apresentar variantes conflituosas, mas parece que é essa diversidade e fragilidade que tem fortalecido a pesquisa em educação, no sentido de definir nosso discurso.

Quanto mais pesquisadores, professores e outros sujeitos estiverem pensando, questionando e discutindo sobre educação, as práticas educativas, seu contexto e sua realidade, mais informações e possíveis soluções surgirão. Mesmo porque a concepção de ciência e pesquisa não é mais algo pronto e acabado; não é a posse de verdades imutáveis. Cervo (2007, p. 7) diz que a pesquisa "é entendida como uma busca constante de explicações, de revisão e de reavaliação de seus resultados". Diante dos limites dessa subjetividade e da impossibilidade de conhecermos o todo, delimitamos e estreitamos nossa problemática. Optamos por realizar uma pesquisa junto à Rede Municipal de Educação de Catalão/GO, investigando informações acerca dos cursos ofertados entre os anos de 2000 a 2010 aos professores que atuam na Educação Infantil.

Tendo como referenciais a legislação brasileira, em especial a Lei de Diretrizes e Bases para Educação Nacional (LDBEN 9.394/1996), o Plano Nacional de Educação (2001-2010) e as discussões para o novo PNE (2011- 
2020), que garantem o direito à formação continuada, e à luz de autores que se debruçam sobre o tema da formação docente, é que embasamos nossas discussões.

Ao iniciarmos a pesquisa, a primeira opção de coletar dados, era junto à Secretaria Municipal de Educação, o que se tornou inviável, por falta de acesso aos documentos. Diante disso, partimos para a coleta de dados com os professores, criando um roteiro de entrevista assim, a escolha dos entrevistados foi se afunilando de acordo com alguns elementos da pesquisa. Um deles foi o recorte temporal de 2000 a 2010, estabelecido em razão da necessidade de distanciamento do pesquisador com o pesquisado. Por esse ser um período posterior a mudanças na área da educação, tais como a expansão dos cursos de pós-graduação, os cursos via UAB no Brasil, e também por ser um período de troca de administração local, como prefeitos, secretários de educação e outros, coincide também com uma política de governo que tem como pano de fundo incentivar a pós-graduação em todo o país. A partir desse recorte temporal, somente os professores que estavam atuando nas classes de Educação Infantil nesse período foram analisados. Outro critério relevante diz respeito à problemática e abrangência do foco de nossa pesquisa, que é discutir a formação do professor da Educação Infantil. Por isso, apenas foram convidados a participar da pesquisa os professores de creches e pré-escola. Optamos em não identificar os professores, para preservação da identidade e pela questão ética de se manterem no anonimato, de forma a evitar qualquer represália e, também, por acreditar que, não se identificando, eles teriam maior liberdade de expressão.

Selecionado o grupo dos sujeitos a serem pesquisados, tínhamos uma tarefa: escolher quais instituições da cidade de Catalão/GO seriam visitadas, bem como decidir se seriam todas, já que 26 (vinte e seis) é um numero relevante, e o objetivo era localizar onde estava o grupo estratégico de professores préselecionados nos itens anteriores, que atuavam no período analisado.

Inicialmente, fizemos uma divisão geográfica, mapeando instituições que se localizassem ao norte, sul, leste, oeste e uma no centro da cidade, de forma que pudéssemos abranger toda a cidade nas suas especificidades, entrevistando profissionais de diferentes idades e lugares da cidade, respeitando as particularidades de cada um. Foram, então, mapeadas cinco escolas que, por questões de ética, não serão identificadas pelos nomes, criamos uma tabela para melhor apresentar os dados: 
Tabela 1 - Localização da região/ Escolas e dos entrevistados

\begin{tabular}{cccc}
\hline REGIÃO & ESCOLAS & $\begin{array}{c}\text { No }^{0} \text { DE PROFESSORES } \\
\text { ENTREVISTADOS }\end{array}$ & $\begin{array}{c}\text { DENOMINACÃO DO } \\
\text { PROFESSOR }\end{array}$ \\
\hline Norte & Escola 1 & 4 & $\mathrm{~A}, \mathrm{~B}, \mathrm{C}, \mathrm{D}$ \\
\hline Sul & Escola 2 & 2 & $\mathrm{E}, \mathrm{F}$ \\
\hline Leste & Escola 3 & 4 & $\mathrm{G}, \mathrm{H}, \mathrm{I}, \mathrm{J}$ \\
\hline Oeste & Escola 4 & 2 & $\mathrm{~L}, \mathrm{M}$ \\
\hline Centro & Escola 5 & 2 & $\mathrm{~N}, 0$ \\
\hline
\end{tabular}

A "Escola 1", situada mais ao norte da cidade, caracteriza-se por ser um escola mais distante do centro da cidade atende cerca de duzentos e quatro crianças entre zero e cinco anos de idade consideradas de baixa renda. A Escola 2 localizada ao sul da cidade também é uma escola pequena, com cerca de cem alunos mais favorecidos economicamente. Ao leste da cidade, a Escola 3 caracteriza-se por ser uma escola "modelo" em questões de bom funcionamento dentro da própria rede, haja visto que é construída dentro das exigências da Educação Infantil: é a única escola da rede que possui piscina, refeitório adequado, biblioteca, brinquedoteca e atende cerca de trezentas e oitenta crianças de zero a dez anos. A Escola 4, localizada a oeste, também distante do centro, atende duzentos e quarenta e três crianças carentes e algumas consideradas de grupo riscos. A Escola 5 localizada mais ao centro, é uma escola pequena, com cerca de cento e oitenta alunos que varia de três a dez anos, mais favorecidos economicamente.

Nessas instituições, identificamos os catorze professores sujeitos de nossa pesquisa, que os pré-requisitos por nós estabelecidos. Vencida essa etapa, passamos para decodificar, agrupar e analisar os dados obtidos. Para facilitar nosso entendimento, as respostas foram interpretadas observando dois fatores: a) Qual a concepção de formação continuada dos sujeitos? b) Qual a percepção sobre a formação continuada ofertada pela rede municipal na década de 2000 a 2010? Para respondermos tais questionamentos, buscamos na legislação o referencial para confrontar com os relatos das entrevistas.

A divergência das respostas obtidas nos leva a questionar a concepção de formação continuada por parte dos professores e se eles têm clareza das leis que regem o Estatuto do Professor no âmbito municipal, estadual e federal. Ao serem indagados se os órgãos públicos têm investido o suficiente na formação de professores, respeitando, assim, o Artigo $61 \$ 1^{\circ}$ da Constituição Federal Brasileira de 1988, a maioria respondeu que "não", e justificou, mas outros 
responderam que "sim". Vejamos a concepção de uma da professora G, que atua há vinte e quatro anos somente na Educação Infantil na Rede Municipal de Catalão/GO e que, atualmente está numa turma de Jardim II: "Sim, porque temos cursos todos os anos, inclusive em todas as áreas que atuamos".

Quando indagada em que esses cursos contribuíram em sua prática em sala de aula ela responde: "me ajudou a superar várias dúvidas que eu tinha quando alfabetizava." Podemos perceber que a concepção aqui apresentada acredita que a Secretaria Municipal de Educação de Catalão/GO (SMECGO) tem investido nos cursos de capacitação do profissional docente, inclusive em diferentes áreas do saber. Porém apenas três dos entrevistados concordam com esta posição, os outros professores foram peremptórias em afirmar que não, como podemos ler na fala da "Prof". A" que atua a dezenove anos na rede, e atualmente no jardim II:

Prof ${ }^{a}$. A" que atua a dezenove anos na rede, e atualmente no jardim II :

"Não a formação continuada é aquela que nunca para, você sempre esta fazendo algum curso de aperfeiçoamento profissional, já fez cursos que pouco auxiliou na minha prática, mas foi a troca de experiências com as colegas de outras escolas que valeu a pena.”

Podemos assim perceber que a maioria dos professores tem conhecimento do que regem as leis, das suas condições precárias de trabalho especialmente no âmbito Municipal, pois a mesma professora D entrevista na Escola 1 diz: "Não, uma vez que nem a licença para aprimoramento profissional garantido na Lei n. ${ }^{\circ} .872$ de 18/11/2.011, cap. IV, seção I Artigo 62: o poder público Municipal quer garantir ao professor.” Esse documento mencionado é o novo Estatuto do Magistério aprovado recentemente pela SMECGO que será apresentado posteriormente vejamos o que garante a Constituição Federal Brasileira quanto à responsabilidade dos Estados e Municípios:

$\int 1^{\circ}$ A União, o Distrito Federal, os estados e os municípios, em regime de colaboração, deverão promover a formação inicial, a continuada e a capacitação dos profissionais de magistério.

$\int 2^{\circ}$ A formação continuada e a capacitação dos profissionais de magistério poderão utilizar recursos e tecnologias de educação a distância

Observamos que o Município de Catalão/GO não desconsidera a lei enquanto uma instância superior, no entanto, encontrou um jeito de cumprir 
parcialmente tais exigências, pois, no Estatuto do Magistério da Rede Municipal de Catalão/GO, promulgado em 18/11/2011, Lei n. 2.872, assegura no capítulo IV, art.62, que:

A licença para aprimoramento e qualificação consiste no afastamento do profissional da área da educação, sem prejuízo de seu vencimento ou remuneração, para frequentar em tempo regular, cursos de pós-graduação, em nível de Mestrado e Doutorado.

\ I - deve ter o profissional da área da educação, no mínimo, 03 (três) anos de atividade de magistério.

\ III - só será permitida a licença simultânea de no máximo 02 (dois) professores da rede municipal de ensino, a serem escolhidos pela Secretaria Municipal de Educação, priorizando as modulações e as necessidades didáticas da cada professor e da unidade escolar. \ IV - no caso da concorrência de interessados em número superior ao definido no inciso anterior, será deferido o pedido do profissional da área da educação que tenha maior tempo de magistério no serviço público municipal e, caso persista o empate, terá preferência o professor mais idoso;

Porém, os \ I, III, IV, vão, de certa forma, restringindo e afunilando as oportunidades de estudo. Sabemos que na rede Municipal de Catalão/GO tem ao todo cerca de quatrocentos professores atuando do berçário ao $8^{\circ}$ ano do ensino fundamental, e são ofertadas apenas duas bolsas de estudo o que acreditamos ser insuficientes diante da demanda de professores que querem se aperfeiçoarem conformem relatou a professora $\mathrm{D}$ anteriormente.

Embora nem todos tenham se posicionado em comum acordo em relação à concepção de formação continuada, todos têm a percepção de que a formação continuada seja importante e necessária para nossa prática em sala de aula. A maioria concorda que eles não têm esse direto assegurado pelo poder público e que, quando este é chamado à responsabilidade de ofertar cursos, estes não são de qualidade, e assim não cumprem o objetivo de um curso de formação continuada como apresentamos no início deste texto, que acreditamos ser um curso capaz de levar o indivíduo a refletir sobre suas práticas, como podemos ler no relato da professora $\mathrm{B}$, quando ela explica os cursos chamados "semanas pedagógicos" que são ofertados geralmente no início de cada ano letivo aos professores pela SMEC/GO chamados equivocadamente de cursos de formação continuada: 
Não. "Tem cursos que acontecem só uma vez por ano, normalmente no inicio e, nem sempre são "bons", algumas são pura "enrolação", como que para cumprir o que determina a lei, porém não são tão eficientes, na maioria são falhos”.

É evidente que "Semanas pedagógicas" e formação continuada para nós e conforme as entrevistas, para os professores, caracterizam situações diferentes. A primeira "semanas pedagógicas" deveria servir para que os professores planejassem suas atividades anuais, tivessem encontros e trocas de experiências, já formação continuada deve ser realmente continua de acordo com a atuação dos professores.

Essa situação, portanto, mostra-se diferente do que prescreve a Lei de Diretrizes e Bases da Educação Nacional (LDBEN/9.394/1996), no Art. 61, em especial nos fundamentos II e III, no qual ser professor é:

Art. 61. Consideram-se profissionais da educação escolar básica os que, nela estando em efetivo exercício e tendo sido formados em cursos reconhecidos,

Parágrafo único. A formação dos profissionais da educação, de modo a atender às especificidades do exercício de suas atividades, bem como aos objetivos das diferentes etapas e modalidades da educação básica, terá como fundamentos:

I - a presença de sólida formação básica, que propicie o conhecimento dos fundamentos científicos e sociais de suas competências de trabalho;

II - a associação entre teorias e práticas, mediante estágios supervisionados e capacitação em serviço;

III - o aproveitamento da formação e experiências anteriores, em instituições de ensino e em outras atividades.

Nos fundamentos II e III, que dizem respeito à associação entre teoria e prática e o aproveitamento da formação e experiências anteriores, podemos verificar, através do depoimento de uma professora, que, na realidade, isso não acontece, pois quando perguntamos se elas têm momentos de encontro e troca de experiências, a professora B disse:

"Trocar experiências com as colegas sobre as atividades que fizemos e que deram certo seria muito bom [...]. Poder ouvir o que elas fizeram também, mas não temos tempo pra encontros. 
A secretaria deveria fazer cursos de encontros das professoras da mesma serie, de troca de experiência e não esses cursos sem sentido como aquele do Meio Ambiente."

Podemos perceber nessa fala uma vontade da professora em discutir e refletir sobre as dificuldades de sua prática, de seus problemas. Isso, portanto, pode ser interpretado como um "clamor" por formação continuada, pois o que parece existir são poucos projetos de "reciclagem de professores", de treinamento, mas não formação continuada, propostos pela Secretaria Municipal de Educação de Catalão-GO. Como relatou outra professora, a entrevistada denominada $\mathrm{H}$ :

\begin{abstract}
"Não. Os cursos acontecem só uma vez por ano, normalmente no inicio e, e nem sempre são "bons”, alguns são pura “enrolação”, como que para cumprirem o que determina a lei, porém não são tão eficientes. Claro que existem alguns muito bons e úteis como o pro-letramento, que foi uma professora da rede que ministrou as aulas e era a tutora do curso, mas em sua maioria eles são falhos.”.
\end{abstract}

Outra professora é ainda mais pontual quando diz:

"A prefeitura oferece cursos no inicio de cada ano, porem são curso sem aproveitamento porque somos obrigados a participar, muitas vezes são pessoas da secretaria que dão os cursos e acaba que os professores começam a reclamar, fazer reivindicações ao secretário (quando ele aparece) e o que deveria ser um momento de troca de experiência, de encontro com os colegas da rede acaba sendo brigas e desgaste para nós.” (prof. ․ C).

Dessa maneira, parece que esses cursos promovidos têm funcionado mais para expressar a insatisfação com a administração local do que realmente como constituintes de momentos de reflexão da prática e de trocas de experiências, como nos coloca a entrevista: Assim, parece que os cursos ofertados que se tornam desinteressantes e monótonos, uma vez que os professores não têm momentos e oportunidades de falar e expressar suas aflições e reivindicações a SMEC/GO. Sabemos que, de acordo com os investimentos feitos em Educação e com os vários incentivos do MEC, a Prefeitura de Catalão/GO tem condições efetivas de oferecer cursos de excelência, trazendo profissionais capacitados, inclusive de outros estados. 
De acordo com a Meta 16 do PNE/2011-2020, é plano político garantir a formação continuada a todos. Mas, como perceber essa efetivação na prática? Sabemos que capacitar exige investimentos e gastos, e, como também é objetivo da maioria dos municípios e estados brasileiros promover uma educação com baixo custo, percebe-se poucos esforços nos setores de formação do profissional. Assim, o professor em pleno século XXI parece estagnar-se quanto à formação continuada, e o órgão responsável (SME) também não cumpre seu dever. Enquanto que os vários segmentos da sociedade priorizam o profissional "atualizado", são poucos os professores da Educação Infantil que buscam por si mesmos meios e recursos de se aperfeiçoarem. Abicalil (2010) chama de responsabilidade Individual aquela que compete não exclusivamente aos órgãos públicos, mas também aos professores, que também têm parcela de responsabilidade de procurar, enquanto profissionais, fazer o melhor.

Nesse sentido, consideramos que muitas descobertas e reflexões ainda poderão ser feitas a fim de atingirmos nossa proposta de pesquisa. Seguimos acreditando que mudanças somente são possíveis a partir da reflexão sobre a prática. Portanto, esperamos juntos poder pensar em alternativas que possam contribuir para a melhoria da qualidade do ensino na cidade de Catalão/GO, através das trocas de experiências e das reflexões referentes às políticas públicas na área da educação e no âmbito formação continuada.

\section{CONSIDERAC̣ÕES FINAIS}

Compreender esse universo de desafios enfrentados pelos professores da Educação Infantil junto às políticas públicas de educação não parece tarefa fácil ou agradável. Se de um lado temos um professor oprimido pelos baixos salários, com carga horária abusiva, péssimas condições públicas de trabalho e desacreditando no seu papel de agente transformador da realidade; do outro temos uma política governamental que mede a qualidade do ensino, que promove cursos de formação aligeirados, que desvaloriza o profissional da educação com um "teto" salarial insuficiente e que, acima de tudo, não oferece as mínimas condições de trabalho. Entendemos que tudo isso, de forma conjunta, tem causado um profundo incômodo na categoria docente. Seja em qualquer nível de ensino: O Infantil, o Fundamental ou Superior, vivemos à mercê dos caminhos econômicos e políticos trilhados pelo país.

Como bem sabemos, a educação é fruto dessa disputa por poder, interesses e valores sociais da nossa cultura. Por isso, os caminhos e os rumos que apontamos a cada dia, seja na pesquisa ou na criação de leis, também contribuem para formar o discurso próprio da Educação. 
Nesse sentido, consideramos que muitas descobertas e reflexões deverão ser realizadas a fim de atingirmos maiores resultados no campo educacional. Desse modo, acreditamos que os primeiros passos e talvez, os mais importantes foram dados, que são as reflexões, discussões, a inquietações e o desconforto, pois, a partir deles algumas direções serão apontadas. 


\section{Title: SEM TRADUÇÃO}

\section{Abstract}

The Law of Guidelines and Bases (LDB), enacted in 1996, already understood that the age to six years of age is the first step in the education of the child. So it should be offered in nurseries or equivalent entities to three years and preschools from four to six years old. Currently, tailoring teaching for nine years, the LDB was amended by Law No. 11,114 / 05 and thereby be diminished supply of early childhood education. It happens that, even today, many understand early childhood education from zero to three years as a stage in which children only need care and affection. Consequently, the training of professionals had not deserved the treatment. This research proposes to examine the practices of continuing education that the City Department of Education Catalan / GO released for qualification of teachers of early childhood education, from 2000 to 2010. Our objective analyzes refer to reflections on social responsibility, educational policies and evaluation indexes of government. The ethnographic research focused on teachers from five educational institutions in preliminary analyzes investigated on teacher performance and working conditions that are submitted (as) teachers (as) Early Childhood Education of the City of Catalan / GO. Data strengthens our perception of the need for continued training as an ongoing process of negotiations and discoveries that provide new grounds and educational experiences in pedagogical action.

Keywords: Continuing Education; Early Childhood Education; Public Policy. 


\section{REFERÊNCIAS}

ANDRÉ, Marli. Pesquisa em educação: buscando rigor e qualidade. Cadernos de Pesquisa. N.113, p. 53.2001 BRASIL, Ministério da Educação. Plano Nacional de Educação PNE 2001-2010. Disponível em: //www. Planalto. Gov. br/civil//Leis.2001. Acesso em out 2011.

BRASIL, Ministério da Educação. Lei de Diretrizes e Bases da Educação Nacional n. 9394/96 Disponível em: //www. Planalto. Gov. br/civil//leis.2001. Acesso em out 2011.

BRASIL, Constituição da Republica Federativa do Brasil. Braślia (1988)

COELHO, IIdeu Moreira. In: SILVA, S. P. \& GONÇALES, A. M․ (orgs.) Formação de professores das novas diretrizes curriculares: Escola, saber e Formaç̃ão de professores, Catalão, 2008.

CERVO, Amado Luiz. Metodologia cientifica. 6. ed. São Paulo: Prearson P. 2007.

CHARLOT, Bernad, A pesquisa educacional entre conhecimentos, políticas e práticas: especificidades e desafios de uma área de saber. Revista Brasileira de Educação, v. 11, n.31. Jan./abr. 2006.

DOURADO, Luiz Fernando. Plano Nacional de Educação (2011- 2020): Avaliação e perspectivas.

GATTI, Bernadete. Implicacõoes e perspectivas da pesquisa educacional no Brasil contemporâneo. Cadernos de Pesquisa, n.113, jul.2001.

OLIVEIRA, João Ferreira. A Educação superior no contexto atual e o PNE 2011-2020: avaliaç̦ão e perspectivas. Goiânia: 2011. In. Plano Nacional de Educação (2011-2020): Avaliação e perspectivas. DOURADO, Luiz Fernandes (Org.). - Goiânia: Editora UFG; Belo Horizonte: 2011.

SADALLA, Ana Maria F. A. Apresentaç̃õo. In Formação Continuada, Interdisciplinaridade e inclusão social/ MENDONÇA, M. R (Org.). Catalão: UFG-CAC, 2008. 